\title{
Ergonomics
}

\section{The effects of a simulated occupational kneeling exposure on squat mechanics and knee joint load during gait}

\section{Liana Michele Tennant, Helen Christina Chong \& Stacey Marie Acker}

To cite this article: Liana Michele Tennant, Helen Christina Chong \& Stacey Marie Acker (2017): The effects of a simulated occupational kneeling exposure on squat mechanics and knee joint load during gait, Ergonomics, DOI: 10.1080/00140139.2017.1411529

To link to this article: https://doi.org/10.1080/00140139.2017.1411529

Accepted author version posted online: 01

Dec 2017.

Submit your article to this journal $\widetilde{ }$

Џ Article views: 12

Q View related articles $\sqsubset$

View Crossmark data $\nearrow$ 
Publisher: Taylor \& Francis

Journal: Ergonomics

DOI: http://doi.org/10.1080/00140139.2017.1411529

D Check for updates

The effects of a simulated occupational kneeling exposure on squat mechanics and knee joint load during gait

Liana Michele Tennant ${ }^{1 a}$, Helen Christina Chong $^{1 b}$, Stacey Marie Acker ${ }^{1 \mathrm{c}}$

${ }^{1}$ Department of Kinesiology, Faculty of Applied Health Sciences, University of Waterloo, Ontario, Canada

aEmail: Imtennan@uwaterloo.ca

bEmail: hcchong@uwaterloo.ca

‘Email: stacey.acker@uwaterloo.ca

Correspondence Address:

Dr. Stacey Acker

Department of Kinesiology

Faculty of Applied Health Sciences

University of Waterloo

200 University Avenue West

Waterloo, ON

Canada N2L $3 G 1$

1-519-888-4567 ext. 31338

stacey.acker@uwaterloo.ca 
Funding: Funding was provided by the National Sciences and Engineering Council of Canada (NSERC) and the Ontario Provincial Government (OGS) (LT) and through an NSERC Discovery grant \#418647 (SA).

Conflict of Interest Disclosure: No conflicts of interest to declare

Abstract

Occupational kneeling is associated with an increased risk for tibiofemoral knee osteoarthritis. Forces on the knee in the kneeling posture, as well as the greater incidence of meniscus tears among workers likely contribute to the increased risk. We hypothesize that an additional mechanism may contribute - altered neuromuscular control due to prolonged high knee flexion. Forty participants ( 20 male, 20 female) completed an evaluation of gait and squatting before, immediately following, and 30 minutes following a 30-minute simulated occupational kneeling exposure. An increase in the peak external knee adduction moment and a delay in vastus medialis activation onset during walking was observed post-kneeling, as well as increased frontal plane knee motion during squatting. This was the first investigation to find changes in high flexion transitions as a result of kneeling. Greater frontal plane knee motion may increase the risk for meniscal tears, and subsequently, knee osteoarthritis.

Practitioner Summary

A 30-minute simulated occupational kneeling exposure resulted in small but significant gait changes. The greatest effect was on frontal plane knee movement during squatting, which is especially relevant to occupations requiring frequent kneeling/squatting. This increased motion may indicate an increased risk of injury, which supports a link to knee osteoarthritis.

Key Words: biomechanics, ergonomics, musculoskeletal disorders, knee, osteoarthritis 


\section{Introduction}

The prevention of work-related musculoskeletal overuse injuries is in the best interests of both employers and workers to keep costs low and maintain the workers' quality of life. Occupations that require frequent or prolonged high knee flexion postures, such as floor laying, tile setting, and low seam coal mining, have all been associated with an increased risk for the development of both tibiofemoral and patellofemoral osteoarthritis (Coggon et al. 2000; Cooper et al. 1994; Jensen et al. 2012; Kellgren and Lawrence 1952; Manninen et al. 2002; Sandmark, Hogstedt, and Vingård 2000). For example, among male floor layers, one study of workers in Sweden found that $79 \%$ of knee osteoarthritis cases that required total knee arthroplasty could be attributed to the working environment (Järvholm et al. 2008). In addition, a study of workers in Denmark showed that not only were male floor layers at increased risk of developing knee osteoarthritis, the risk increased in relation to the number of years in that occupation (Andersen et al. 2012) suggesting that cumulative load is an important consideration in the development of the disease. However, not all studies show an association between occupational high knee flexion postures and knee osteoarthritis, and therefore the relationship is still contested (Ezzat and Li 2014; McWilliams et al. 2011). Contributing to the controversy is that few studies have found a definitive dose-response relationship between occupational workload and disease development (Seidler et al. 2008).

Regardless of the discrepancies, both Denmark and Germany recognize knee osteoarthritis as an occupational disease. The German Ministry of Health and Social Affairs uses the following definition: "Osteoarthritis of the knee by occupational kneeling or comparable occupational load with a cumulative exposure of at least 13,000 hrs. and a minimum exposure time of one hour per shift" (Seidler et al. 2008). Therefore, given the mounting evidence that occupational high knee flexion postures can increase knee osteoarthritis risk, the acceptance of knee osteoarthritis as an occupational disease in some countries, and that knee osteoarthritis progression is irreversible and subsequent surgical interventions are expensive, invasive, and may make return-to-work difficult, the prevention of occupation-mediated knee osteoarthritis is imperative.

The mechanism linking occupations that require high knee flexion postures and knee osteoarthritis is unclear. The majority of researchers have focused on the static full-flexion posture itself, based on the understanding that the static application of high joint forces may place excessive load on the knee joint cartilage, contributing to cartilage degeneration and knee osteoarthritis initiation. Modelling studies have estimated tibiofemoral loading in high knee flexion postures and have found that loads range from 2.8 - 7.3x body weight (BW) (Dahlkvist, Mayo, and Seedhom 1982; Nagura et al. 2002; Smith et al. 2008). However, a significant limitation of these high flexion knee models is that the load-distributing effect of thigh-calf contact is neglected. Therefore, forces acting on the tibiofemoral joint in high knee flexion postures are likely smaller than the model-estimated values. Data from instrumented tibias support this possibility, indicating that the magnitude of force at the knee in postures such as kneeling can be less than 50\% BW (compared to loads of 220 and 350\% BW in gait and stair climbing) (Zhao et al. 2007). In addition, when moving through the knee range of motion, one study has found that tibiofemoral forces are greatest not when resting in the fully flexed posture, but 
just before full knee flexion is reached (Kutzner et al. 2010). Therefore, while forces acting on the joint cartilage in high knee flexion may contribute to knee osteoarthritis risk, it is possible that their role has been overestimated.

Another potential mechanism linking occupational high knee flexion postures and knee osteoarthritis is that repetitive loading of the knee in these postures increases the risk for meniscal tears (Jensen et al. 2012; McMillan and Nichols 2005; Reid et al. 2010; Snoeker et al. 2013). Meniscal tears impair the healthy dispersion of loads across the knee joint, which could promote further joint injury and cartilage degradation (Badlani et al. 2013; Englund et al. 2009; Englund 2009; Muthuri et al. 2011). Individuals whose work requires high knee flexion demonstrate a greater incidence of meniscal lesions when compared to workers in lower knee flexion occupations (Baker et al. 2003; Jensen et al. 2012). As recently as 2010, the International Labour Organization also recognizes, "meniscal lesions following extended periods of work in a kneeling or squatting position," as an occupational disease. Therefore, it seems likely that the increased risk of knee osteoarthritis associated with occupational high knee flexion postures is at least partially due to the greater probability of meniscal tears.

More recently, an alternative mechanism has been proposed to link high knee flexion postures to knee osteoarthritis. Prolonged or frequent exposure to high knee flexion may alter gait patterns due to the isolated or combined effects of changes in joint proprioception and ligamentous laxity induced by the end range-of-motion posture (Kajaks and Costigan 2015). Based on the understood function of ligaments as check-reins at the end range of motion, and that posterior cruciate ligament rupture may occur when an individual falls to the floor with the knee hyperflexed and the ankle plantarflexed (Prentice 2011), it is reasonable to hypothesize that ligamentous creep could occur from occupational full flexion kneeling. Experimentally, cruciate ligamentous creep has been shown to alter neuromuscular control when measuring lower limb muscle activation patterns (Cheng et al. 2014; Chu et al. 2003). From a mechanistic perspective, it is theorized that micro-rupture of the collagen fibres that occurs with ligamentous creep causes 'feedback signal corruption' due to acute inflammation, which leads to alterations in neuromuscular control (Solomonow 2006; Solomonow 2009). Based on these findings, prolonged occupational kneeling may induce changes in neuromuscular control.

Given the importance of ligaments in proprioception and motor control of the knee (Hewett, Paterno, and Myer 2002), any feedback signal corruption due to time spent kneeling may impair protective mechanisms during subsequent activities, such as gait or squatting, therefore potentially contributing to joint damage (Knoop et al. 2011). For example, gait adaptations in workers who regularly adopt high knee flexion postures have been reported (Gaudreault et al. 2013). These findings are supported by work by Kajaks and Costigan (2015) that measured 10 healthy young males and found an elevated external knee adduction moment (KAM) during walking after a 30-minute static full-flexion kneeling exposure. Because the KAM has been associated with medial knee joint loads (Miyazaki et al., 2002; Zhao et al., 2007), the authors suggested that this change in neuromuscular control could be associated with the increased incidence of knee osteoarthritis observed among occupational kneelers (Kajaks \& Costigan, 2016). 
To illustrate the importance of gait adaptations in workers who kneel, consider that while the exposure to kneeling postures may vary between floor layers who work in a team and those who are self-employed, floor layers commonly spend between $38-66 \%$ of their working time in high knee flexion postures (Jensen, Rytter, and Bonde 2010). The remainder of the work day is spent on preparation or finishing tasks, such as measuring and preparing the floor and materials (cutting planks or tiles to size), preparing quick set, moving materials from the truck to the work area, nailing in floor boards, and so on, all of which require ambulation. Gait is also an activity of daily living that is required outside of working hours. Therefore, if gait alterations persist after work is completed, the effects may always be present and carry over into non-work related activities. Studies investigating osteoarthritis initiation and progression in anterior cruciate ligament ( $\mathrm{ACL}$ )-deficient individuals have suggested that following ACL rupture, altered loading conditions in the knee disrupt normal cartilage cell turnover, initiating cartilage degradation (Andriacchi, Koo, and Scanlan 2009). Possibly, a similar mechanism occurs in occupational kneelers, such that time spent in high knee flexion postures induces significant changes in neuromuscular control and subsequent movement patterns (whether due to ligamentous laxity, similar to ACL-deficient individuals, or changes in proprioception, or a different mechanism), which may contribute to their increased risk for knee osteoarthritis.

Three gait characteristics were explored in the current study, due to their associations with an increased risk for the development of knee osteoarthritis: KAM, peak rate of loading (ROL), and quadriceps activation onset. First, the external KAM has been linked to the risk for medial compartment tibiofemoral osteoarthritis (Miyazaki et al. 2002), and is often used as a measure of medial compartment loading (Hurwitz et al. 1998; Jackson et al. 2004). Secondly, high rates of physiological loading can initiate the process of cartilage degeneration (Radin 2004; Brandt, Dieppe, and Radin 2009) since cartilage is a visco-poroelastic tissue that is sensitive to ROL (Richard, Villars, and Thibaud 2013) and could be damaged by impulsive loading during gait (Blackburn et al. 2016; Collins and Whittle 1989; Liikavainio et al. 2007; Radin et al. 1984). Lastly, quadriceps activation onset immediately prior to initial contact of gait acts to reduce the rate of loading at the knee through eccentric contraction (Jefferson et al. 1990; Lindstedt, LaStayo, and Reich 2001). Therefore, if this mechanism is compromised (e.g. onset occurs too late or too early to provide optimal force distribution effects), this measure may provide additional insight as to the link between occupational kneeling and knee osteoarthritis initiation.

A squatting task was also analysed. Both the mean and peak frontal plane motion of the knee joint during squatting were measured in this study since transitions to-and-from the floor are performed frequently by workers in occupations that require frequent and prolonged kneeling; therefore, this activity may be another potential source for cumulative trauma leading to knee osteoarthritis. For example, in our own unpublished pilot work, floor layers working alone performed transitions to or from the floor once every 2-3 minutes. Movement of the knee during a squat has never been directly linked to knee osteoarthritis risk. However, movement characteristics, such as increased frontal plane knee motion, have been linked to traumatic knee injuries (Hewett et al. 2005), such as ligament tears or meniscus injury, which in turn could lead to knee osteoarthritis (Englund 2010).

In summary, based on the findings of previous work (Gaudreault et al. 2013; Kajaks and Costigan 2015), time spent in high knee flexion postures has the potential to alter neuromuscular control and 
affect movement patterns during other, biomechanically dissimilar activities. However, the evidence is sparse, and previous works have been limited to a kinematics-only evaluation, small subject groups evaluating a single sex, or static exposures that may not adequately represent occupational tasks. Therefore, the purpose of this study was to determine whether a simulated occupational kneeling exposure results in measurable changes that may be correlated with knee osteoarthritis risk. It was hypothesized that the first peak of the external KAM and peak vertical ROL during gait would increase following kneeling. Similarly, following the kneeling exposure, quadriceps activation onset was expected to be delayed with respect to initial contact of gait. Lastly, it was hypothesized that the kneeling exposure would result in maladaptive changes in neuromuscular control during squatting to-and-from the floor, such that both the peak and mean frontal plane knee motion during squatting would increase.

\section{Methods}

Forty healthy, young adults participated (Table 1). Participants were excluded if they had a current lower limb injury, a previous knee ligament or meniscal injury, or were employed in an occupation that required frequent or prolonged kneeling in the previous 12 months. The study was approved by the university's office of research ethics committee, and participants provided informed consent.

\section{Protocol}

Prior to instrumentation, participants performed a leg dominance test (Schneiders et al. 2010) and completed questionnaires to screen for exclusion criteria. Data were only collected from the dominant leg. Participants wore low-heeled running shoes and loose athletic shorts. Participants were instrumented with surface EMG and motion tracking markers, and forces were measured using force plates (see Electromyography, Motion Capture, and Force Data respectively for instrumentation details and data processing).

Gait

Following instrumentation, participants completed baseline gait trials over an $8.5 \mathrm{~m}$ walkway with force plates imbedded in the floor. Gait speed was constrained to $1.4 \mathrm{~m} / \mathrm{s}( \pm 0.05 \mathrm{~m} / \mathrm{s}$ ) (Bohannon 1997; Kumar et al. 2015) using a photoelectric timing gate system with gates spaced equally on either side of the force platforms (3-meter inter-gate distance), at a height where the gates were triggered by the head or shoulders of the participants. Only trials with appropriate gait speed and with foot isolation on a single force plate were used in analysis. Three such gait trials were collected for each participant, randomized with three loaded gait trials, where participants carried $20 \%$ of body mass. (The loaded gait trials are not analysed as part of this study).

\section{Squat Transitions}

Next, participants performed squat transitions to-and-from the floor as a measure of neuromuscular control (Frost et al. 2015) that is occupationally relevant. Participants were asked to 
descend and rise five times using whichever method would allow them to achieve the deepest squat. As such, foot position, angle of toe-out, and ankle posture were not constrained in order to accommodate individuals with differing balance, flexibility, body composition, and joint morphologies. Participants were required to practice the transitions until they could perform them in time with a metronome set at 88 BPM -2 beats descend, 1 beat pause, 2 beats to rise (Almosnino, Kingston, and Graham 2013). The first three squat trials where all markers were visible and squat speed was appropriate were used for analysis.

\section{Kneeling Exposure}

Participants then completed a 30-minute simulated occupational kneeling exposure. This acute kneeling exposure consisted of repeated cycles of 2 minutes of single-arm supported kneeling (sometimes referred to as 3-point kneeling), followed by 30 seconds of full-flexion kneeling (Figure 1). During the single-arm supported kneeling component, participants completed a non-specific cardsorting task (e.g. sorting cards by suit) as a non-hand-loaded surrogate for occupational floor work such as setting tiles or flooring planks. The width of the card-sorting workspace during single-arm supported kneeling was normalized to each participant's arm span and divided widthwise into four equal quadrants. Each 2-minute exposure of single-arm supported kneeling (Figure 1) was divided into two, 1minute exposures in a random quadrant. A 30-second standing break occurred every 10 minutes (Figure 1).

During the kneeling exposure, pain in the lower limbs was assessed on a $100 \mathrm{~mm}$ visual analog scale before the kneeling trial began, at 5-minute intervals during the kneeling exposure, and following the exposure. During the exposure, the pain measure was always recorded while the participant rested in the full-flexion kneeling posture (Figure 1). Immediately following the kneeling exposure, participants completed gait and squatting trials. The participant then rested while seated until 30 minutes had passed since the end of the kneeling exposure, at which time gait and squatting trials were repeated.

\section{Electromyography}

Electrical activity of the vastus medialis was recorded using wireless surface electromyography (Wave Plus EMG, Cometa, Cisliano, Italy), sampled at $2100 \mathrm{~Hz}$. This system has non-modifiable 1000x signal amplification and a band-pass filter of $10-500 \mathrm{~Hz}$. The skin over the muscle belly was shaved, and lightly abraded with an exfoliating gel (NuPrep Skin Prep Gel, Weaver and Company, Aurora, CO, USA) and rubbing alcohol. Two surface $\mathrm{Ag}-\mathrm{AgCl}$ electrodes (Ambu ${ }^{\circledR}$ Blue Sensor N, Denmark) were applied in the direction of the muscle fibres with a two-centimetre inter-electrode distance. The electrodes were placed approximately two finger widths medial and 3-4 finger widths superior to the superolateral border of the patella, in accordance with SENIAM guidelines (Hermens et al. 1999). Manual muscle test contractions were used to confirm appropriate electrode placement and ensure a clean signal.

Following a 5-minute warmup of walking on a treadmill at a comfortable pace, participants completed maximal voluntary isometric contractions, performed while the participant was seated in a 
knee extension machine, with the knee flexed to $45^{\circ}$ (Kingston et al. 2016). Participants were given verbal encouragement as they isometrically contracted their knee extensors against resistance, with specific instruction to ramp into their maximal effort. Two trials were recorded, with a minimum of 1 minute of rest between trials. Additional trials were completed as necessary until the participant felt that they had reached a true maximum.

No standard method exists to identify muscle activation onset in the literature. To determine vastus medialis activation onset in this study, the electromyographic signal was linear enveloped by removing DC bias, applying a dual-pass high-pass $2^{\text {nd }}$ order Butterworth filter at $20 \mathrm{~Hz}$ to remove lowfrequency noise contamination, full-wave rectification, and a $50 \mathrm{~Hz}$ dual-pass low-pass $2^{\text {nd }}$ order Butterworth filter. Activation onset was defined as a the first frame where the $50 \mathrm{~ms}$ moving average window of the signal exceeded baseline levels by at least three standard deviations, for 25 ms (Hodges and Bui 1996). Onset was identified during gait within the $250 \mathrm{~ms}$ window prior to initial foot contact.

\section{Motion capture}

Kinematics of the lower limb were measured using a 6-bank, 18 camera three-dimensional motion capture system (Optotrak Certus \& 3020, NDI, Waterloo, ON, CA). Active marker clusters consisting of five infrared diodes were firmly affixed to the lateral aspect of the foot, shank, and thigh of the participant's dominant leg, as well as the sacrum (Figure 2). Segment coordinate systems were defined based on relevant bony landmarks, which were identified using a digitizing probe and tracked with the marker clusters. These coordinate system definitions comply with ISB recommendations (Wu and Cavanagh 1995). See Supplement A for coordinate system definitions. Position data were sampled at $100 \mathrm{~Hz}$. The data were padded by including at least 1 second of data at the beginning and end of each trial (Howarth and Callaghan 2009), and filtered using a $2^{\text {nd }}$ order dual-pass low-pass Butterworth filter at a cut-off of $6 \mathrm{~Hz}$ (Winter et al. 1990).

Frontal plane knee motion during squatting was defined as displacement of the functional knee joint centre normal to the body-fixed plane created by the distal foot (defined as the midpoint between the first and fifth metatarsal heads), the ankle joint (defined as the midpoint between the medial and lateral malleoli), and the functional hip joint centre (Frost et al. 2015). The peak and mean knee deviations are reported as an absolute value, in meters. Medial and lateral deviations were not specified because the intent of the measure was to quantify negative adaptations (i.e. greater distance of the knee away from the plane, regardless of the direction of the deviation). Evaluating the knee trajectory in this way is thought to be a more insightful measure of frontal plane knee motion compared to an analysis of the ab/adduction angle because it takes into account the position of the foot.

\section{Force Data}

Force and moment data were sampled at $2100 \mathrm{~Hz}$ (OR6-7, AMTI, Watertown, MA, USA). The amplifiers applied a $2^{\text {nd }}$ order low-pass critically damped filter of $1050 \mathrm{~Hz}$ across all channels. Joint moments were calculated in Visual 3D (V 4.96.13, C-Motion, Germantown, MD, USA) using the unfiltered force data. The knee moment was resolved into the tibial coordinate system (Mündermann 
et al. 2004) and normalized as a percentage of participant body weight times height in meters (\%BW*H) to remove the potentially confounding effects of sex (Moisio et al. 2003). The peak external KAM was evaluated as the maximum value during the first half of the stance phase of gait (hereafter this outcome measure will be referred to simply as the 'peak moment'). Unfiltered force data was also used to identify initial foot contact during gait ( $0 \%$ stance phase), using a vertical force threshold of $20 \mathrm{~N}$ (Zeni Jr., Richards, and Higginson 2008).

Force plate data were processed with a dual-pass low-pass $2^{\text {nd }}$ order Butterworth filter with a cut-off of $100 \mathrm{~Hz}$ for the calculation of the peak vertical ROL. The peak vertical ROL was measured as the peak value of the first derivative of the body weight normalized vertical force data, giving units of body weight / second (BW/s) (Mikesky, Meyer, and Thompson 2000).

\section{Statistics}

Three gait measures (peak moment, peak vertical ROL, and vastus medialis activation onset) and two squatting measures (mean and peak frontal plane knee motion) were analysed. For each participant, outcomes were averaged across trials to get a mean for each time point: before ('pre') and after ('post') the kneeling exposure, and 30 minutes after kneeling was completed ('30post'). Hypotheses were tested using a mixed general linear model ANOVA design (SAS Version 9.4, Cary, NC, USA). In this design, 'sex' was a between-subjects factor, and 'time' (pre/post/30post) was the withinsubject factor. To evaluate the homogeneity of group mean variance, Levene's test was used. Mauchly's test was used to test the hypothesis that the variance of the differences between conditions was equal when independent variables had more than two levels. When assumptions of sphericity were violated, the Greenhouse-Geisser corrected $p$-value was used to determine statistical significance. To determine the significance between means when significant interaction effects were found, planned contrasts analysis was used (Field and Miles 2010).

\section{Results}

All participants were able to complete the kneeling exposure protocol. Only 5/40 participants reported an increase in pain that could be considered clinically relevant ( $8 \mathrm{~mm}$ or greater from baseline), for at least one measured site, at the end of the kneeling exposure (Nelson-Wong and Callaghan 2014). All post-kneeling measures were collected within the 30-minute window between the end of the kneeling exposure and the start of the second post-kneeling collection, although four participants required five or more trials to capture a single stride of gait that met all requirements for a usable trial (i.e. foot isolation on the force plate, correct walking speed, all markers visible). Measured means and standard deviations (in brackets) are reported in Table 2, separated by sex.

\section{Gait - Knee adduction moment}

There was a main effect of the kneeling exposure on the peak moment $\left(F_{2,76}=3.07, \mathrm{p}=.0301\right)$ (Figure 3a). The peak moment was significantly greater immediately following the kneeling exposure $\left(F_{1,38}=9.05, \mathrm{p}=0.0046, r=0.44\right)$. The peak moment measured 30 minutes post-kneeling was not 
significantly different from the baseline value $\left(F_{1,38}=1.84, \mathrm{p}=0.1835, r=0.21\right)$, nor were the post- and 30 minutes post-kneeling measures found to be different $\left(F_{1,38}=2.56, p=0.1183, r=0.25\right)$. Females had a significantly greater peak moment compared to the males $\left(F_{1,38}=14.83, p=.0004, r=.53\right)$ (Figure $3 b$ ). No significant interaction effect was found between the effects of the kneeling exposure and sex on the peak moment $\left(F_{2,76}=2.75, \mathrm{p}=.0859\right)$.

\section{Gait - Peak vertical rate of loading}

No effect of the kneeling exposure was found on the peak vertical $\operatorname{ROL}\left(F_{2,76}=1.21, p=0.2394\right)$, nor was there a main effect of $\operatorname{sex}\left(F_{1,38}=2.37, p=0.1316, r=.24\right)$ or an interaction effect $\left(F_{2,76}=0.36, p\right.$ $=0.6274$ ) (Figure $4 a, b)$.

\section{Gait - Quadriceps activation onset}

Muscle activation onset was determined relative to initial contact of gait as absolute time (in seconds) and as a percentage of the gait cycle (Table 2). There was a main effect of the kneeling exposure on the activation onset timing of vastus medialis $\left(F_{2,76}=5.18, p=.0078\right)($ Figure 5a). Vastus medialis activation onset pre-kneeling was significantly earlier than onset postkneeling $\left(F_{38,1}=13.10, \mathrm{p}=.0009, r=.51\right)$, as well as onset at 30 minutes post-kneeling $\left(F_{38,1}=4.84, \mathrm{p}=\right.$ $.0339, r=.34)$. Activation onset times were not statistically different between post- and 30 minutes post-kneeling time points $\left(F_{1,38}=.67, p=.4176, r=.13\right)$. There was no main effect of sex on activation onset $\left(F_{1,38}=0.00, \mathrm{p}=.9655, r=0\right)$ (Figure $\left.5 \mathrm{~b}\right)$, nor was there an interaction effect between sex and the effects of the kneeling exposure $\left(F_{2,76}=.77, p=.4650\right)$.

\section{Squat Transitions - Mean and peak frontal plane knee deviation}

The kneeling exposure had a significant main effect on the mean frontal plane knee deviation $\left(F_{2,76}=4.64, \mathrm{p}=.0126\right)$ (Figure 6a). Mean deviation of the knee joint center post-kneeling was greater than the baseline value $\left(F_{1,38}=6.20, p=.0173, r=.37\right)$ and remained greater compared to baseline values at 30 minutes post-kneeling $\left(F_{1,38}=7.79, \mathrm{p}=.0082, r=.41\right)$. There was no difference between values at the post-and 30 minutes post-kneeling time points $\left(F_{1,38}=.03, p=.8710, r=.03\right)$. There was no main effect of sex $\left(F_{1,38}=.06, p=.8076, r=.04\right)$ (Figure $\left.6 b\right)$. There was no significant interaction effect for mean deviation during the squat transitions $\left(F_{2,76}=0.26, p=.7680, r=.06\right)$.

A main effect of the kneeling exposure was also found for peak deviation of the knee joint center in the frontal plane $\left(F_{2,76}=4.41, p=.0155\right)$ (Figure $\left.6 c\right)$. The peak deviation was significantly greater post-kneeling $\left(F_{1,38}=8.52, \mathrm{p}=.0059, r=.43\right)$, but not at 30 minutes post-kneeling $\left(F_{1,38}=4.07, \mathrm{p}\right.$ $=.0508, r=.31)$ in comparison to baseline. There was no main effect of $\operatorname{sex}\left(F_{1,38}=.63, p=.4307, r=.13\right)$ (Figure $6 \mathrm{~d}$ ). There was no significant interaction effect for maximum deviation during the squat transitions $\left(F_{2,76}=0.02, \mathrm{p}=.9819, r=.02\right)$. 


\section{Discussion}

\section{Gait - Knee adduction moment}

The 30-minute dynamic kneeling exposure elicited a statistically significant change in the peak moment during gait, supporting the hypothesis that the peak external KAM would increase following the simulated occupational kneeling exposure. This finding also agrees with earlier work that found an increase in the KAM following a 30-minute static full-flexion kneeling exposure (Kajaks and Costigan 2015). Although both studies found statistically significant effects of the kneeling exposure on the KAM, a number of differences should be acknowledged. The previous study analysed the effects of a static kneeling exposure, whereas the current study analysed the effects of a dynamic exposure. In addition, the authors in the previous work reported the root mean square difference between conditions in $\mathrm{Nm} / \mathrm{kg}$. Using the average participant height reported in that study $(1.80 \mathrm{~m})$, the stated difference of $0.07 \mathrm{Nm} / \mathrm{kg}$ converts approximately to $0.4 \% \mathrm{BW} * \mathrm{H}$. In the current study, the difference in peak moment was $0.11 \% \mathrm{BW}^{*} \mathrm{H}$ between baseline and post-kneeling. Therefore, while it is interesting to note that even with the differences in methods, to date, two studies have shown an increase in the peak knee adduction moment during gait following a 30-minute kneeling exposure, it is also important to acknowledge that the magnitude of change observed in both studies is small, and that this change did not persist after 30 minutes in our study.

In an effort to determine whether a difference of $0.11 \% \mathrm{BW} * \mathrm{H}$ has clinical significance, peak KAM differences that distinguished between osteoarthritis severities were extracted from the gait literature. A difference in the peak KAM of $0.86 \% \mathrm{BW} * \mathrm{H}$ (Mündermann et al. 2004) or $1.3 \% \mathrm{BW} * \mathrm{H}$ (Sharma et al. 1998) separated patients with less severe knee OA (K/L grade $\leq 2)$ from those with more severe knee $\mathrm{OA}(\mathrm{K} / \mathrm{L}$ grade $\geq 3)$. A difference of approximately $0.6 \% \mathrm{BW} * \mathrm{H}$ separated symptomatic and asymptomatic individuals with severe knee osteoarthritis (Mündermann et al. 2004). In a six-year longitudinal study, a peak KAM difference of $2.1 \% \mathrm{BW} * \mathrm{H}$ separated patients with and without radiographic disease progression (Miyazaki et al. 2002). In a more recent study, a significant correlation was found between the peak KAM and medial tibial surface bone marrow lesions in patients with knee osteoarthritis (Chang et al. 2015), which have been independently associated with knee osteoarthritis risk (Roemer et al. 2010). This correlation was associated with a peak KAM difference of $0.55 \% \mathrm{BW} * \mathrm{H}$. Therefore, based on clinically and statistically significant differences in the peak KAM reported in the literature of $0.5 \% \mathrm{BW} * \mathrm{H}$ or greater among knee osteoarthritis patients, caution should be taken when evaluating the relevance of the current findings of an increase in $0.11 \% \mathrm{BW}{ }^{*} \mathrm{H}$ in healthy young people on disease risk in kneeling workers. At the same time, it is inappropriate to presume that an acute, 30 minute exposure is representative of the effects of cumulative kneeling loads experienced by occupational kneelers who develop knee osteoarthritis. This is an important consideration, since some studies suggest that cumulative occupational kneeling loads (which were not captured in the current study) increase knee osteoarthritis risk (Seidler et al., 2008).

Peak moments calculated in the current study at baseline were similar to peak moments previously reported in young, healthy, males and females during shod gait $(2.48 \pm 0.40 \% \mathrm{BW} * \mathrm{H}$ 
(Dowling, Fisher, and Andriacchi 2010)). Although sex differences are not often reported, the finding in the current study that females exhibited a greater peak KAM compared to males supports the findings of another gait study where participants were shod (male: $2.83 \pm 0.49 \% \mathrm{BW}{ }^{*} \mathrm{H}$, female: $3.06 \pm 0.46$ \%BW*H (Barrios and Strotman 2014) (Note, that the values from Barrios \& Strotman (2014) were divided by 9.81 and multiplied by 100 to convert from $\mathrm{Nm} / \mathrm{kg}^{*} \mathrm{H}$ to $\% \mathrm{BW}{ }^{*} \mathrm{H}$ ). The main effect of sex in the current study persisted despite using a moment normalization technique intended to reduce the effects of sex on knee joint moment calculations (Moisio et al. 2003).

\section{Gait - Peak vertical rate of loading and vastus medialis activation onset}

In support of the hypothesis, vastus medialis onset was significantly delayed following the kneeling exposure. Vastus medialis onset occurred approximately $10 \mathrm{~ms}$ closer to initial contact immediately following the kneeling exposure, and remained delayed by $7 \mathrm{~ms} 30$ minutes post-kneeling (Figure 5). Because pre-activation of the quadriceps in anticipation of external loads during gait is thought to be a protective mechanism to reduce the rate of loading at the knee, thereby preserving cartilage integrity (Jefferson et al. 1990), based on our initial analysis, the delay in onset supports the hypothesis that exposure to occupational kneeling leads to negative adaptations in neuromuscular control.

It is, unfortunately, difficult to determine whether this delay in onset is sufficient to alter loading on the knee joint in a biologically significant manner. Contrary to the hypothesis, there was no effect of the kneeling exposure on the peak vertical ROL, which was used in this study as a surrogate measure of joint loading. This finding might suggest that the delay in activation onset in the current study is inconsequential from a biological perspective, because delays of greater magnitude (such as paralysis of the quadriceps) have been shown to cause increased rates of overall knee loading (Jefferson et al. 1990). Therefore, while the finding is interesting to note, further research is necessary to determine whether such a delay is sufficient to alter joint loading, and, if similar neuromuscular control changes occur in muscles that cross the hip and ankle that could then affect joint loads at the knee.

\section{Squat transitions}

The control of the knee during squat transitions was impaired following the kneeling exposure. Both the peak and the mean frontal plane knee motion increased following kneeling, and mean deviation remained elevated when measured again 30 minutes post-kneeling, which supported the hypotheses. Although not necessarily directly linked to knee osteoarthritis risk, frontal plane knee motion has been linked to increased injury risk (Hewett et al. 2005). Because some workers must perform many transitions to-and-from the ground in a single day, it is possible that negative adaptations in frontal plane knee motion following prolonged kneeling could increase the risk for meniscal tears, which have been shown to be a common injury among workers who kneel (McMillan and Nichols 2005; Reid et al. 2010; Snoeker et al. 2013). Both meniscal tears and subsequent meniscectomies are associated with an increased risk for the development of knee osteoarthritis (Cicuttini et al. 2002; Englund et al. 2009). Therefore, based on research that has shown that certain movement patterns can be risk factors for injury (Hewett et al. 2005; Pohl et al. 2008), it is possible that workers may be at 
greater risk of injury when the knee is in a more highly deviated posture, which could lead to the development of knee osteoarthritis. This finding supports the theory suggested by Jensen (2012) that kneeling workers may be at greater risk of meniscal tears compared to workers in trades that do not require kneeling, due to altered movements when transitioning to-and-from the floor.

\section{Limitations}

Some of the changes following kneeling, although statistically significant, were small in magnitude, and direct comparisons to clinical populations may suggest that the results do not indicate biologically relevant changes. Therefore, it is important to note that the changes observed following a 30 minute kneeling exposure among healthy young participants should be considered in the context of a typical workday. Workers in occupations that require high knee flexion postures may spend anywhere from $38-66 \%$ of the day working in kneeling postures (Jensen, Rytter, and Bonde 2010), meaning they could be exposed to much more than 30 minutes of kneeling in a single day. Thus, while the effects of 30 minutes of kneeling might be considered small, the changes were statistically significant; given a cumulative occupational exposure over weeks, months, or years, an increased magnitude of change in the variables measured might be expected should tissue tolerance decrease due to repeated exposure with insufficient tissue recovery (Kumar 2001). An amplification in the magnitude of change in neuromuscular control is supported by the few studies analysing the dose-response effect of occupational kneeling on knee osteoarthritis risk (Klussmann et al. 2010; Seidler et al. 2008). Whether the mechanism of change is related to alterations in joint laxity, muscle or tendon stretch, or changes in proprioception resulting from the kneeling exposure is not known.

In addition, while using a young population to assess the effects of a kneeling exposure ensured that existing knee osteoarthritis would not confound the results, it is possible that younger individuals are more resilient to the effects of a kneeling exposure. Lifting is an additional occupational exposure that has been associated with knee osteoarthritis when combined with kneeling that this study does not address (Amin et al. 2008).

\section{Conclusion}

Neuromuscular control in healthy young adults was affected by a 30-minute simulated occupational kneeling exposure. The peak KAM was greater, and quadriceps activation onset was delayed at initial contact during gait. The effect of delayed onset persisted 30 minutes post-kneeling. Although the clinical significance of the small changes in gait is uncertain, the statistical significance points to these variables as areas for future study, particularly in evaluations of the cumulative effects of occupational kneeling. Based on differences found between workers in knee-straining and non-kneestraining occupations (Gaudreault et al. 2013), more research is needed on long-term exposure to high knee flexion postures. In addition, frontal plane knee motion increased. The increase persisted for 30 minutes. Greater frontal plane knee motion may be associated with elevated risk of traumatic knee injury, such as meniscal tears, which are associated with an increased risk for the development of knee osteoarthritis. No sex differences were observed in response to the kneeling exposure; however, women exhibited greater peak KAMs compared to males. 
This study complements previous work that investigated the effects of kneeling exposures on gait kinematics (Gaudreault et al. 2013) and peak KAMs (Kajaks and Costigan 2015) through our analysis of changes in peak vertical ROL and quadriceps activation onset relative to initial contact during gait (which have been found to be affected by knee osteoarthritis) and frontal plane knee motion (which can be an indicator of injury risk) during squatting. In agreement with the general findings of this previous work, the current study confirms the possibility that occupational kneeling can change movement patterns and loading outside of work tasks and working hours. Further research is needed on longer exposures, with particular attention to cumulative and persisting effects, the effects on other muscles of the lower limb that affect loads at the knee, and on the mechanisms through which a kneeling exposure might affect neuromuscular control.

Bibliography

Almosnino, S., D. Kingston, and R. B. Graham. 2013. "Three-Dimensional Knee loint Moments during Performance of the Bodyweight Squat: Effects of Stance Width and Foot Rotation." Journal of Applied Biomechanics 29 (1): 33-43.

Amin, S., J. Goggins, J. Niu, A. Guermazi, M. Grigoryan, D. J. Hunter, H. K. Genant, and D. T. Felson. 2008. "Occupation-Related Squatting, Kneeling, and Heavy Lifting and the Knee Joint: A Magnetic Resonance Imaging-Based Study in Men." Journal of Rheumatology 35 (8): 1645-49.

Andersen, S., L. C. Thygesen, M. Davidsen, and K. Helweg-Larsen. 2012. “Cumulative Years in Occupation and the Risk of Hip or Knee Osteoarthritis in Men and Women: A Register-Based Follow-up Study." Occupational and Environmental Medicine 69 (5): 325-30.

Andriacchi, T. P., S. Koo, and S. F. Scanlan. 2009. "Gait Mechanics Influence Healthy Cartilage Morphology and Osteoarthritis of the Knee." Journal of Bone and Joint Surgery - Series A 91 (SUPPL. 1): 95-101.

Badlani, J., C. Borrero, S. Golla, C. Harner, and J. Irrgang. 2013. "The Effects of Meniscus Injury on the Development of Knee Osteoarthritis: Data from the Osteoarthritis Initiative." The American Journal of Sports Medicine 41 (6): 1238-1244.

Baker,P., R. Reading, C. Cooper, and D. Coggon. 2003. "Knee Disorders in the General Population and their Relation to Occupation." Occupational and Environmental Medicine 60 (10): 794-797.

Barrios, J. A. and D. E. Strotman. 2014. "A Sex Comparison of Ambulatory Mechanics Relevant to Osteoarthritis in Individuals with and without Asymptomatic Varus Knee Alignment." Journal of Applied Biomechanics 30 (5): 632-636.

Blackburn, T. J., B. Pietrosimone, M. S. Harkey, B. A. Luc, and D. N. Pamukoff. 2016. "Quadriceps Function and Gait Kinetics After Anterior Cruciate Ligament Reconstruction." Medicine and 
Science in Sports and Exercise 48 (9): 1664-1670.

Bohannon, R. W. 1997. "Comfortable and Maximum Walking Speed of Adults Aged 20-79 Years: Reference Values and Determinants." Age and Ageing 26 (1): 15-19.

Brandt, K. D., P. Dieppe, and E. Radin. 2009. "Etiopathogenesis of Osteoarthritis." Medical Clinics of North America 93 (1): 1-24.

Chang, A. H., K. C. Moisio, J. S. Chmiel, F. Eckstein, A. Guermazi, P. V. Prasad, Y. Zhang, et al. 2015. "External Knee Adduction and Flexion Moments during Gait and Medial Tibiofemoral Disease Progression in Knee Osteoarthritis." Osteoarthritis and Cartilage 23 (7): 1099-1106.

Cheng, X., T. Zhang, X. Shan, and J. Wang. 2014. "Effect of Posterior Cruciate Ligament Creep on Muscular Co-Activation Around Knee: A Pilot Study." Journal of Electromyography and Kinesiology 24 (2): 2710-2276.

Chu, D., R. LeBlanc, P. D'Ambrosia, R. D'Ambrosia, R. V. Baratta, and M. Solomonow. 2003. "Neuromuscular Disorder in Response to Anterior Cruciate Ligament Creep." Clinical Biomechanics 18 (3): 222-230.

Cicuttini, F. M., A. Forbes, W. Yuanyuan, G. Rush, and S. L. Stuckey. 2002. "Rate of Knee Cartilage Loss After Partial Meniscectomy." Journal of Rheumatology 29 (9): 1954-1956.

Coggon, D., P. Croft, S. Kellingray, D. Barrett, Magnus McLaren, and Cyrus Cooper. 2000. "Occupational Physical Activities and Osteoarthritis of the Knee." Arthritis \& Rheumatism 43 (7): 1443-1449.

Collins, J. J. and M. W. Whittle. 1989. "Impulsive Forces during Walking and their Clinical Implications." Clinical Biomechanics $4(3): 179-187$.

Cooper, C., T. McAlindon, D. Coggon, P. Egger, and P. Dieppe. 1994. "Occupational Activity and Osteoarthritis of the Knee." Annals of the Rheumatic Diseases 53 (2): 90-93.

Dahlkvist, N. J., P. Mayo, and B. B. Seedhom. 1982. "Forces during Squatting and Rising from a Deep Squat." Engineering in Medicine 11 (2): 69-76.

Dowling, A. V., D. S. Fisher, and T. P. Andriacchi. 2010. "Gait Modification Via Verbal Instruction and an Active Feedback System to Reduce Peak Knee Adduction Moment." Journal of Biomechanical Engineering-Transactions of the Asme 132 (7): 071007.

Englund, M. 2010. "The Role of Biomechanics in the Initiation and Progression of OA of the Knee." Best Practice and Research: Clinical Rheumatology 24 (1): 39-46.

Englund, M. 2009. "The Role of the Meniscus in Osteoarthritis Genesis." Medical Clinics of North America 93 (1): 37-43.

Englund, M., A. Guermazi, F. W. Roemer, P. Aliabadi, M. Yang, C. E. Lewis, J. Torner, M. C. Nevitt, B. Sack, 
and D. T. Felson. 2009. "Meniscal Tear in Knees without Surgery and the Development of Radiographic Osteoarthritis among Middle-Aged and Elderly Persons: The Multicenter Osteoarthritis Study." Arthritis and Rheumatism 60 (3): 831-839.

Ezzat, A. M. and L. C. Li. 2014. "Occupational Physical Loading Tasks and Knee Osteoarthritis: A Review of the Evidence." Physiotherapy Canada 66 (1): 91-107.

Field, Andy and Jeremy Miles. 2010. "Mixed Design ANOVA (GLM 5)." In Discovering Statistics using SAS, 436-464: Sage.

Frost, D. M., T. A. C. Beach, J. P. Callaghan, and S. M. McGill. 2015. "The Influence of Load and Speed on Individuals' Movement Behavior." Journal of Strength and Conditioning Research 29 (9): 24172425.

Gaudreault, N., N. Hagemeister, S. Poitras, and J. A. de Guise. 2013. "Comparison of Knee Gait Kinematics of Workers Exposed to Knee Straining Posture to those of Non-Knee Straining Workers." Gait and Posture 38 (2): 187-191.

Hermens, H. J., B. Freriks, R. Merletti, G. Hägg, D. F. Stegeman, J. Blok, G. Rau, and C. Disselhorst- Klug. 1999. SENIAM 8: European Recommendations for Surface ElectroMyoGraphy. Enschede, NL: Roessingh Research and Development.

Hewett, T. E., M. V. Paterno, and G. D. Myer. 2002. "Strategies for Enhancing Proprioception and Neuromuscular Control of the Knee." Clinical Orthopaedics and Related Research, no. 402: 7694.

Hewett, T. E., G. D. Myer, K. R. Ford, R. S. Heidt Jr., A. J. Colosimo, S. G. McLean, Van Den Bogert, A J, M. V. Paterno, and P. Succop. 2005. "Biomechanical Measures of Neuromuscular Control and Valgus Loading of the Knee Predict Anterior Cruciate Ligament Injury Risk in Female Athletes: A Prospective Study. "American Journal of Sports Medicine 33 (4): 492-501.

Hodges, P. W. and B. H. Bui. 1996. "A Comparison of Computer-Based Methods for the Determination of Onset of Muscle Contraction using Electromyography." Electroencephalography and Clinical Neurophysiology - Electromyography and Motor Control 101 (6): 511-519.

Howarth, S. J. and J. P. Callaghan. 2009. "The Rule of $1 \mathrm{~s}$ for Padding Kinematic Data Prior to Digital Filtering: Influence of Sampling and Filter Cutoff Frequencies." Journal of Electromyography and Kinesiology 19 (5): 875-881.

Hurwitz, D. E., D. R. Sumner, T. P. Andriacchi, and D. A. Sugar. 1998. "Dynamic Knee Loads during Gait Predict Proximal Tibial Bone Distribution." Journal of Biomechanics 31 (5): 423-430. International Labour Organization. "ILO List of Occupational Diseases." International Labour 
Organization. Last modified March 25, 2010.

http://www.ilo.org/safework/info/publications/WCMS_125137/lang--en/index.htm.

Jackson, B. D., A. J. Teichtahl, M. E. Morris, A. E. Wluka, S. R. Davis, and F. M. Cicuttini. 2004. "The Effect of the Knee Adduction Moment on Tibial Cartilage Volume and Bone Size in Healthy Women." Rheumatology 43 (3): 311-314.

Järvholm, B., C. From, S. Lewold, H. Malchau, and E. Vingård. 2008. "Incidence of Surgically Treated Osteoarthritis in the Hip and Knee in Male Construction Workers." Occupational and Environmental Medicine 65 (4): 275-78.

Jefferson, R. J., J. J. Collins, M. W. Whittle, E. L. Radin, and J. J. O'Connor. 1990. "Role of the Quadriceps in Controlling Impulsive Forces Around Heel Strike." Proceedings of the Institution of Mechanical Engineers, Part H: Journal of Engineering in Medicine 204 (1): 21-28.

Jensen, L. K., S. Rytter, and J. P. Bonde. 2010. "Exposure Assessment of Kneeling Work Activities among Floor Layers." Applied Ergonomics 41 (2): 319-325.

Jensen, L. K., S. Rytter, J. L. Marott, and J. P. Bonde. 2012. "Relationship between Years in the Trade and the Development of Radiographic Knee Osteoarthritis and MRI-Detected Meniscal Tears and Bursitis in Floor Layers. A Cross-Sectional Study of a Historical Cohort." BMJ Open 2 (3).

Kajaks, T. and P. Costigan. 2015. "The Effect of Sustained Static Kneeling on Kinetic and Kinematic Knee Joint Gait Parameters." Applied Ergonomics 46 (PA): 224-230.

Kellgren, J. H. and J. S. Lawrence. 1952. "Rheumatism in Miners. II. X-Ray Study." British Journal of Industrial Medicine 9 (3): 197-207.

Kingston, D. C., L. M. Tennant, H. C. Chong, and S. M. Acker. 2016. "Peak Activation of Lower Limb Musculature during High Flexion Kneeling and Transitional Movements." Ergonomics 59 (9): 1215-1223.

Klussmann, A., H. Gebhardt, M. Nübling, F. Liebers, E. Quirós Perea, W. Cordier, L. V. von Engelhardt, et al. 2010. "Individual and Occupational Risk Factors for Knee Osteoarthritis: Results of a CaseControl Study in Germany." Arthritis Research and Therapy 12 (3).

Knoop, J., M. P. M. Steultjens, M. van der Leeden, M. van der Esch, C. A. Thorstensson, L. D. Roorda, W. F. Lems, and J. Dekker. 2011. "Proprioception in Knee Osteoarthritis: A Narrative Review." Osteoarthritis and Cartilage 19 (4): 381-88.

Kumar, S. 2001. "Theories of Musculoskeletal Injury Causation." Ergonomics 44 (1): 17-47.

Kumar, D, R. Souza, K. Subburaj, T. MacLeod, J. Singh, N. Calixto, L. Nardo, et al. 2015. "Are there Sex Differences in Knee Cartilage Composition and Walking Mechanics in Healthy and Osteoarthritis 
Populations?" Clinical Orthopaedics and Related Research 473 (8): 2548-2558.

Kutzner, I., B. Heinlein, F. Graichen, A. Bender, A. Rohlmann, A. Halder, A. Beier, and G. Bergmann. 2010. "Loading of the Knee Joint during Activities of Daily Living Measured in Vivo in Five Subjects." Journal of Biomechanics 43 (11): 2164-2173.

Liikavainio, T., J. Isolehto, H. J. Helminen, J. Perttunen, V. Lepola, I. Kiviranta, J. P. A. Arokoski, and P. V. Komi. 2007. "Loading and Gait Symmetry during Level and Stair Walking in Asymptomatic Subjects with Knee Osteoarthritis: Importance of Quadriceps Femoris in Reducing Impact Force during Heel Strike?" Knee 14 (3): 231-238.

Lindstedt, S. L., P. C. LaStayo, and T. E. Reich. 2001. "When Active Muscles Lengthen: Properties and Consequences of Eccentric Contractions." News in Physiological Sciences 16 (6):256-261.

Manninen, P., M. Heliövaara, H. Riihimäki, and O. Suomalainen. 2002. "Physical Workload and the Risk of Severe Knee Osteoarthritis." Scandinavian Journal of Work, Environment and Health 28 (1): 25-32.

McMillan, G. and L. Nichols. 2005. "Osteoarthritis and Meniscus Disorders of the Knee as Occupational Diseases of Miners." Occupational and Environmental Medicine 62 (8): 567-575.

McWilliams, D. F., B. F. Leeb, S. G. Muthuri, M. Doherty, and W. Zhang. 2011. "Occupational Risk Factors for Osteoarthritis of the Knee: A Meta-Analysis." Osteoarthritis and Cartilage 19 (7): 829-839.

Mikesky, A. E., A. Meyer, and K. L. Thompson. 2000. "Relationship between Quadriceps Strength and Rate of Loading during Gait in Women." Journal of Orthopaedic Research 18 (2): 171-175.

Miyazaki, T., M. Wada, H. Kawahara, M. Sato, H. Baba, and S. Shimada. 2002. "Dynamic Load at Baseline can Predict Radiographic Disease Progression in Medial Compartment Knee Osteoarthritis." Annals of the Rheumatic Diseases 61 (7): 617-622.

Moisio, K. C., D. R. Sumner, S. Shott, and D. E. Hurwitz. 2003. "Normalization of Joint Moments during Gait: A Comparison of Two Techniques." Journal of Biomechanics 36 (4): 599-603.

Mündermann, A., C. O. Dyrby, D. E. Hurwitz, L. Sharma, and T. P. Andriacchi. 2004. "Potential Strategies to Reduce Medial Compartment Loading in Patients with Knee Osteoarthritis of Varying Severity: Reduced Walking Speed." Arthritis and Rheumatism 50 (4): 1172-1178.

Muthuri, S. G., D. F. McWilliams, M. Doherty, and W. Zhang. 2011. "History of Knee Injuries and Knee Osteoarthritis: A Meta-Analysis of Observational Studies." Osteoarthritis and Cartilage 19 (11): 1286-1293.

Nagura, T., C. O. Dyrby, E. J. Alexander, and T. P. Andriacchi. 2002. "Mechanical Loads at the Knee Joint during Deep Flexion." Journal of Orthopaedic Research 20 (4): 881-886. 
Nelson-Wong, E. and J. P. Callaghan. 2014. "Transient Low Back Pain Development during Standing Predicts Future Clinical Low Back Pain in Previously Asymptomatic Individuals." Spine 39 (6): E383.

Pohl, M. B., D. R. Mullineaux, C. E. Milner, J. Hamill, and I. S. Davis. 2008. "Biomechanical Predictors of Retrospective Tibial Stress Fractures in Runners." Journal of Biomechanics 41 (6): 1160-1165. Prentice, William, E. 2011. "Chapter 20 - the Knee and Related Structures." In Principles of Athletic Therapy: A Competency-Based Approach, edited by Daniel Arnheim D. 14th ed., 556-604. New York: McGraw-Hill Higher Education, c2011.

Radin, E. L. 2004. "Who Gets Osteoarthritis and Why?" Journal of Rheumatology 31 (SUPPL. 70): 10-15. Radin, E. L., R. B. Martin, D. B. Burr, B. Caterson, R. D. Boyd, and C. Goodwin. 1984. "Effects of Mechanical Loading on the Tissues of the Rabbit Knee." Journal of Orthopaedic Research 2 (3): 221-234.

Reid, C., P. Bush, N. Cummings, D. McMullin, and S. Durrani. 2010. "A Review of Occupational Knee Disorders." Journal of Occupational Rehabilitation 20 (4): 489-501.

Richard, F., M. Villars, and S. Thibaud. 2013. "Viscoelastic Modeling and Quantitative Experimental Characterization of Normal and Osteoarthritic Human Articular Cartilage using Indentation." Journal of the Mechanical Behavior of Biomedical Materials 24: 41-52.

Roemer, F. W., T. Neogi, M. C. Nevitt, D. T. Felson, Y. Zhu, Y. Zhang, J. A. Lynch, et al. 2010. "Subchondral Bone Marrow Lesions are Highly Associated with, and Predict Subchondral Bone Attrition Longitudinally: The MOST Study." Osteoarthritis and Cartilage 18 (1): 47-53.

Sandmark, H., C. Hogstedt, and E. Vingarrd. 2000. "Primary Osteoarthrosis of the Knee in Men and Women as a Result of Lifelong Physical Load from Work." Scandinavian Journal of Work, Environment and Health 26 (1): 20-25.

Schneiders, A. G., S. J. Sullivan, K. J. O'Malley, S. V. Clarke, S. A. Knappstein, and L. J. Taylor. 2010. "A Valid and Reliable Clinical Determination of Footedness." PM and $R 2$ (9): 835-841.

Seidler, A., U, Bolm-Audorff, N. Abolmaali, and G. Elsner. 2008. "The Role of Cumulative Physical Work Load in Symptomatic Knee Osteoarthritis - a Case-Control Study in Germany." Journal of Occupational Medicine and Toxicology 3 (1): 14.

Sharma, L., D. E. Hurwitz, Thonar, E J -M A, J. A. Sum, M. E. Lenz, D. D. Dunlop, T. J. Schnitzer, G. KirwanMellis, and T. P. Andriacchi. 1998. "Knee Adduction Moment, Serum Hyaluronan Level, and Disease Severity in Medial Tibiofemoral Osteoarthritis." Arthritis and Rheumatism 41 (7): 1233- 
1240.

Smith, S. M., R. A. Cockburn, A. Hemmerich, R. M. Li, and U. P. Wyss. 2008. "Tibiofemoral Joint Contact Forces and Knee Kinematics during Squatting." Gait and Posture 27 (3): 376-386.

Snoeker, B. A. M., E. W. P. Bakker, C. A. T. Kegel, and C. Lucas. 2013. "Risk Factors for Meniscal Tears: A Systematic Review Including Meta-Analysis." Journal of Orthopaedic and Sports Physical Therapy 43 (6): 352-367.

Solomonow, M. 2006. "Sensory - Motor Control of Ligaments and Associated Neuromuscular Disorders." Journal of Electromyography and Kinesiology 16 (6): 549-567.

Solomonow, M. 2009. "Ligaments: A Source of Musculoskeletal Disorders." Journal of Bodywork \& Movement Therapies 13 (2): 136-154.

Winter, D. A., A. E. Patla, J. S. Frank, and S. E. Walt. 1990. "Biomechanical Walking Pattern Changes in the Fit and Healthy Elderly." Physical Therapy 70 (6): 340-347.

Wu, G. and P. R. Cavanagh. 1995. "ISB Recommendations for Standardization in the Reporting of Kinematic Data." Journal of Biomechanics 28 (10): 1257-1261.

Zeni Jr., J. A., J. G. Richards, and J. S. Higginson. 2008. "Two Simple Methods for Determining Gait Events during Treadmill and Overground Walking using Kinematic Data." Gait and Posture 27 (4): 710 714.

Zhao, D., S. A. Banks, D. D. D'Lima, C. W. Colwell Jr., and B. J. Fregly. 2007. "In Vivo Medial and Lateral Tibial Loads during Dynamic and High Flexion Activities." Journal of Orthopaedic Research 25 (5): 593-602. 
Table 1. Participant Demographics. Values are reported as: mean (standard deviation) [min, max].

\begin{tabular}{|l|l|l|l|}
\hline & All & Male & Female \\
\hline Age (years) & $21.4(2.5)[18,28]$ & $21.4(2.4)[18,26]$ & $21.4(2.6)[18,28]$ \\
\hline Weight $(\mathrm{kg})$ & $68.8(16.1)[49.1,136.0]$ & $76.6(18.7)[52.7,136.0]$ & $61.0(7.1)[49.1,76.6]$ \\
\hline Height $(\mathrm{m})$ & $1.69(0.10)[1.52,1.92]$ & $1.77(0.10)[1.52,1.92]$ & $1.62(0.10)[1.53,1.79]$ \\
\hline Arm span $(\mathrm{m})$ & $1.70(0.11)[1.51,1.98]$ & $1.79(0.08)[1.64,1.98]$ & $1.61(0.06)[1.51,1.74]$ \\
\hline $\begin{array}{l}\text { Preferred walking speed } \\
\text { (treadmill) }(\mathrm{m} / \mathrm{s})\end{array}$ & $1.19(0.19)[0.82,1.74]$ & $1.23(0.19)[0.88,1.74]$ & $1.14(0.18)[0.82,1.49]$ \\
\hline
\end{tabular}

Table 2. Summary of outcome measures. Values are reported as mean (standard deviation) for all participants, by sex ((M)ale/(F)emale), for each time point. Note, vastus medialis (VM) activation onset values are reported relative to initial contact of gait, both as absolute time $(\mathrm{s})$ and normalized to the length of the gait cycle (\%GC). Measures of peak knee adduction moment (KAM) are reported in \% body weight*height $\left(\% \mathrm{BW}^{*} \mathrm{H}\right)$ and peak vertical rate of loading $(\mathrm{ROL})$ in body weight / second (BW/s).

\begin{tabular}{|c|c|c|c|c|c|c|}
\hline & Measure & Sex & & Pre & Post & 30Post \\
\hline \multicolumn{7}{|l|}{ Activity } \\
\hline \multirow[t]{8}{*}{ Gait } & \multirow{2}{*}{$\begin{array}{l}\text { Peak KAM } \\
\left(\% \text { BW*H) }^{*} \mathrm{H}\right.\end{array}$} & $\mathrm{M}$ & & $2.06(0.71)$ & $2.13(0.68)$ & $2.03(0.94)$ \\
\hline & & $\mathrm{F}$ & & $2.86(0.70)$ & $3.01(0.74)$ & $3.01(0.87)$ \\
\hline & \multirow{2}{*}{$\begin{array}{l}\text { Peak Vertical ROL } \\
\text { (BW/s) }\end{array}$} & $\mathrm{M}$ & & $19.07(3.69)$ & $19.26(4.26)$ & $19.57(5.49)$ \\
\hline & & $\mathrm{F}$ & $\infty$ & $21.52(5.02)$ & $21.11(4.98)$ & $22.03(5.52)$ \\
\hline & \multirow{4}{*}{$\begin{array}{l}\text { VM Activation } \\
\text { Onset }\end{array}$} & $\mathrm{N}$ & (s) & $-0.158(0.028)$ & $-0.144(0.034)$ & $-0.149(0.026)$ \\
\hline & & & $(\% G C)$ & $-14.27(2.50)$ & $-13.08(3.15)$ & $-13.60(2.51)$ \\
\hline & & & $(s)$ & $-0.154(0.030)$ & $-0.148(0.035)$ & $-0.150(0.026)$ \\
\hline & & & (\%GC) & $-14.66(2.76)$ & $-14.01(3.43)$ & $-14.09(2.73)$ \\
\hline \multirow{4}{*}{$\begin{array}{l}\text { Squat } \\
\text { Transitions }\end{array}$} & Frontal Plane & $M$ & & $0.081(0.048)$ & $0.092(0.043)$ & $0.092(0.048)$ \\
\hline & $\begin{array}{l}\text { Knee Deviation - } \\
\text { Mean (m) }\end{array}$ & $F$ & & $0.080(0.038)$ & $0.086(0.040)$ & $0.088(0.042)$ \\
\hline & \multirow{2}{*}{$\begin{array}{l}\text { Frontal Plane } \\
\text { Knee Deviation - } \\
\text { Max }(\mathrm{m})\end{array}$} & $\mathrm{M}$ & & $0.195(0.116)$ & $0.218(0.109)$ & $0.212(0.113)$ \\
\hline & & $\mathrm{F}$ & & $0.222(0.101)$ & $0.243(0.103)$ & $0.238(0.094)$ \\
\hline
\end{tabular}


Figure Captions

Figure 1. Protocol timeline and postures involved in the kneeling exposure.

Figure 2. The marker setup used in data collection. Rigid bodies are firmly attached to the lateral foot, shank, thigh, and sacrum. Note that the sacral marker cluster base is attached to the skin under the participant's t-shirt in this photo.

Figure 3. Peak external knee adduction moment (KAM) (a) Effect of kneeling exposure (pre/post/30post) and (b) Effect of sex (male/female). Asterisk $\left({ }^{*}\right)$ indicates main effect $(p<.05)$. a) pre: $2.46(0.81) \%$ BW*H, post: $2.57(0.83) \% B W^{*} H, 30$ post: $2.52(0.94) \% B W^{*} H ;$ b) female: $2.96(0.76) \% B W^{*} H$, male: 2.07 (0.70) \%BW*H).

Figure 4. Peak vertical rate of loading (ROL) (a) Effect of kneeling exposure (pre/post/30post) and (b) Effect of sex (male/female). a) pre: 20.30 (4.52) BW/s, post: 20.19 (4.67) BW/s, 30post: 20.80 (5.57) $\mathrm{BW} / \mathrm{s} ;$ b) female: 21.55 (5.10) BW/s, male: 19.30 (4.47) BW/s.

Figure 5. Vastus medialis (VM) activation onset with respect to initial contact of gait (at $0 \mathrm{~s}$ ) (a) Effect of kneeling exposure (pre/post/30post) and (b) Effect of sex (male/female). Asterisk $\left({ }^{*}\right)$ indicates main effect $(p<.05)$. a) pre: $-0.156(0.028)$ s, post: $-0.146(0.034)$ s, 30post: $-0.149(0.026)$ s; b) female: -0.151 (0.031) s, male: -0.150 (0.029) s.

Figure 6. Mean frontal plane knee motion (a) Effect of kneeling exposure (pre/post/30post) and (b) Effect of sex (male/female). a) pre: $0.081(0.043) \mathrm{m}$, post: 0.089 (0.041) m, 30post: $0.090(0.044) \mathrm{m}$; b) female: $0.085(0.039) \mathrm{m}$, male: $0.088(0.046) \mathrm{m}$. Peak frontal plane knee motion (c) Effect of kneeling exposure (d) Effect of sex. c) pre: $0.209(0.108) \mathrm{m}$, post: $0.231(0.105) \mathrm{m}$, 30post: $0.225(0.103) \mathrm{m}$; d) female: $0.234(0.098) \mathrm{m}$, male: $0.209(0.111) \mathrm{m}$. Asterisk $\left({ }^{*}\right)$ indicates main effect $(p<.05)$. 


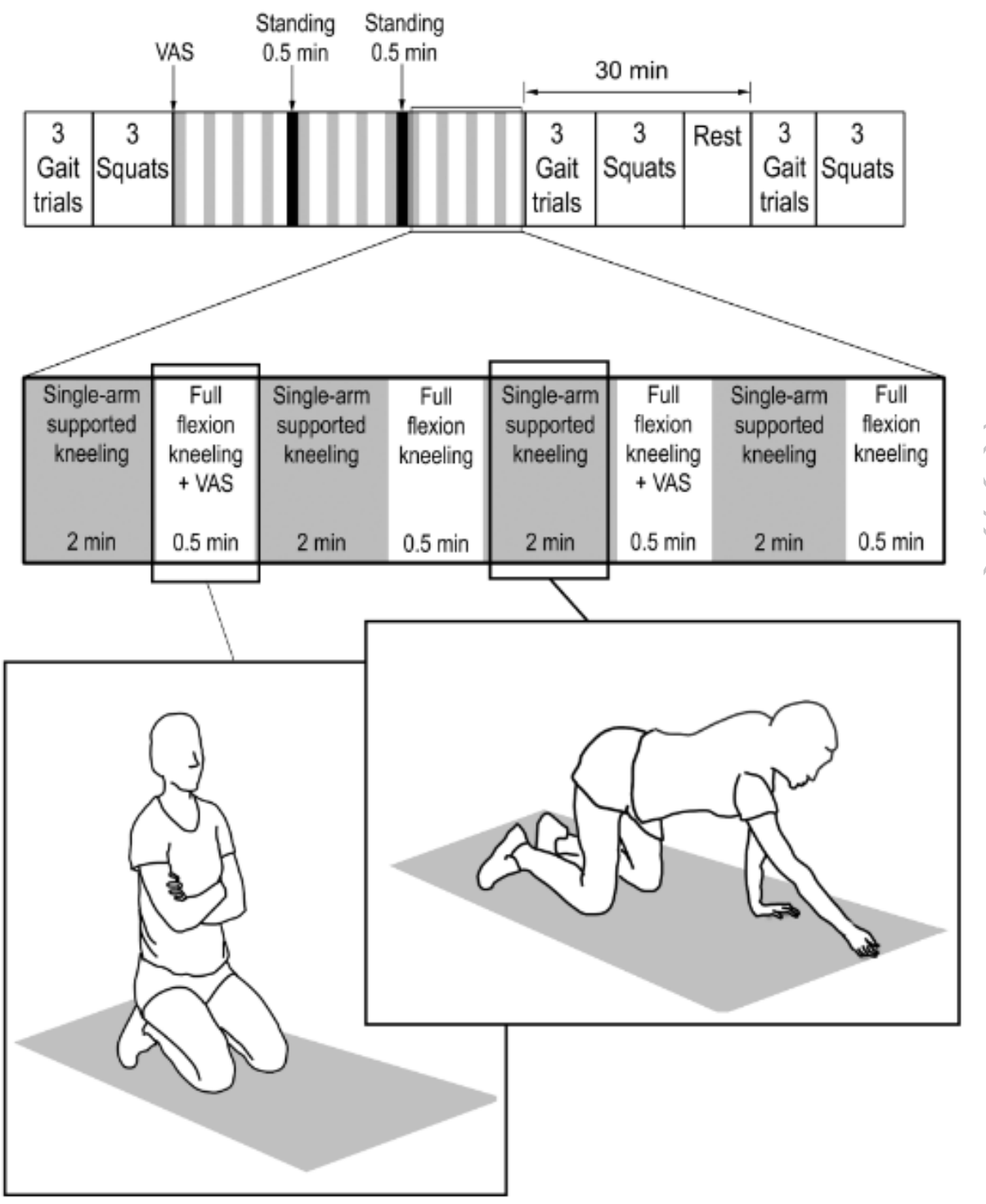




$$
1
$$



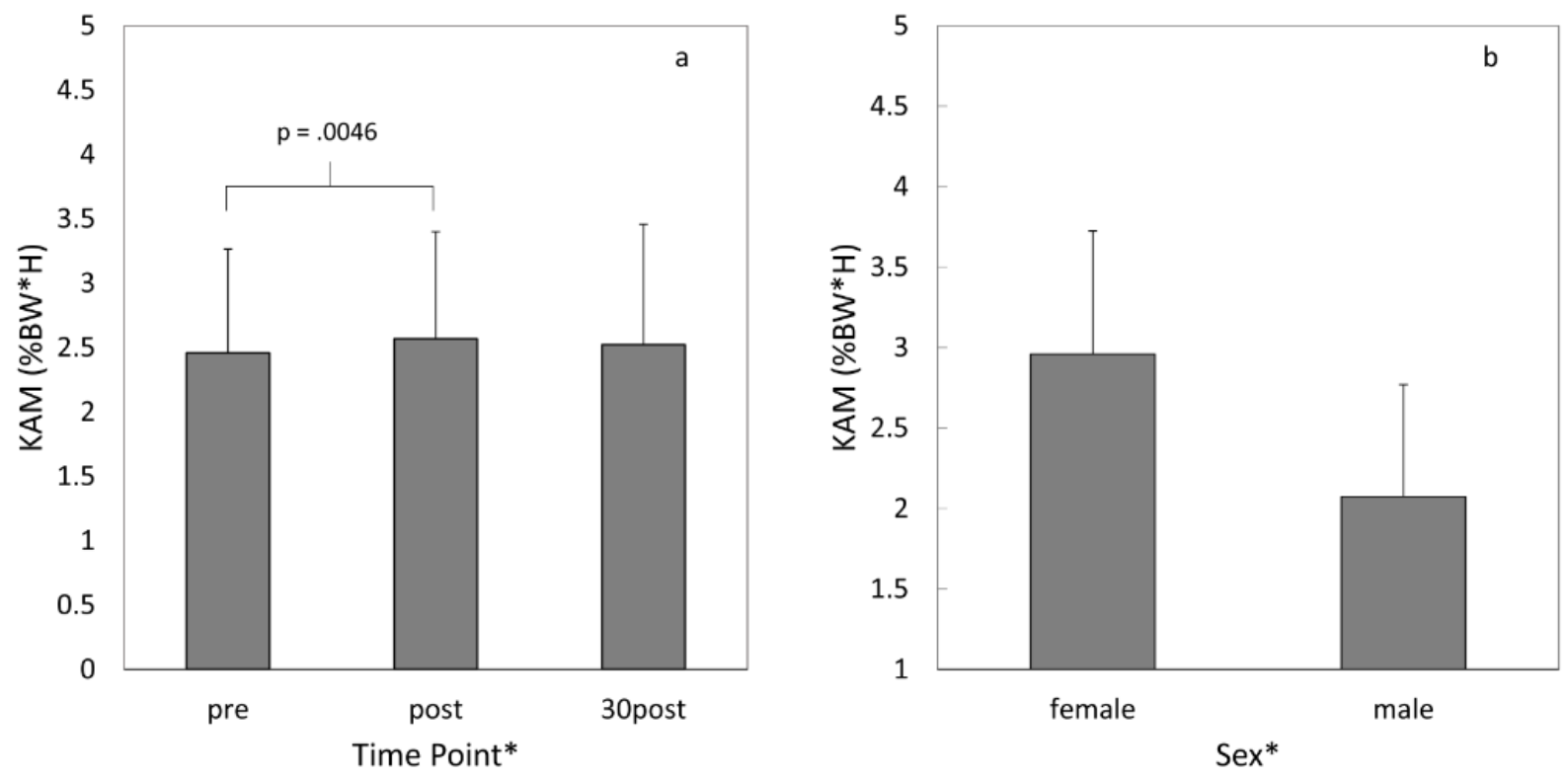

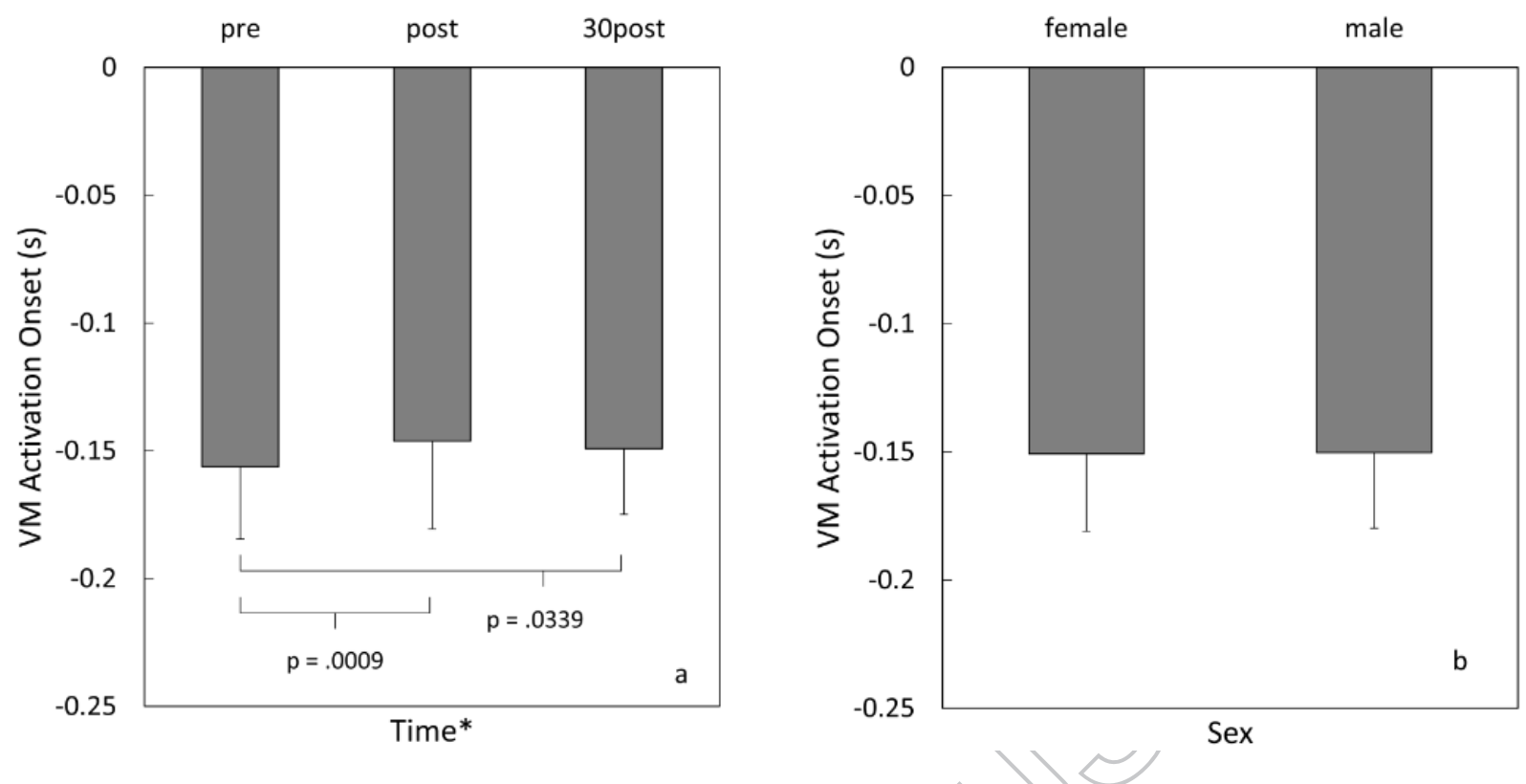

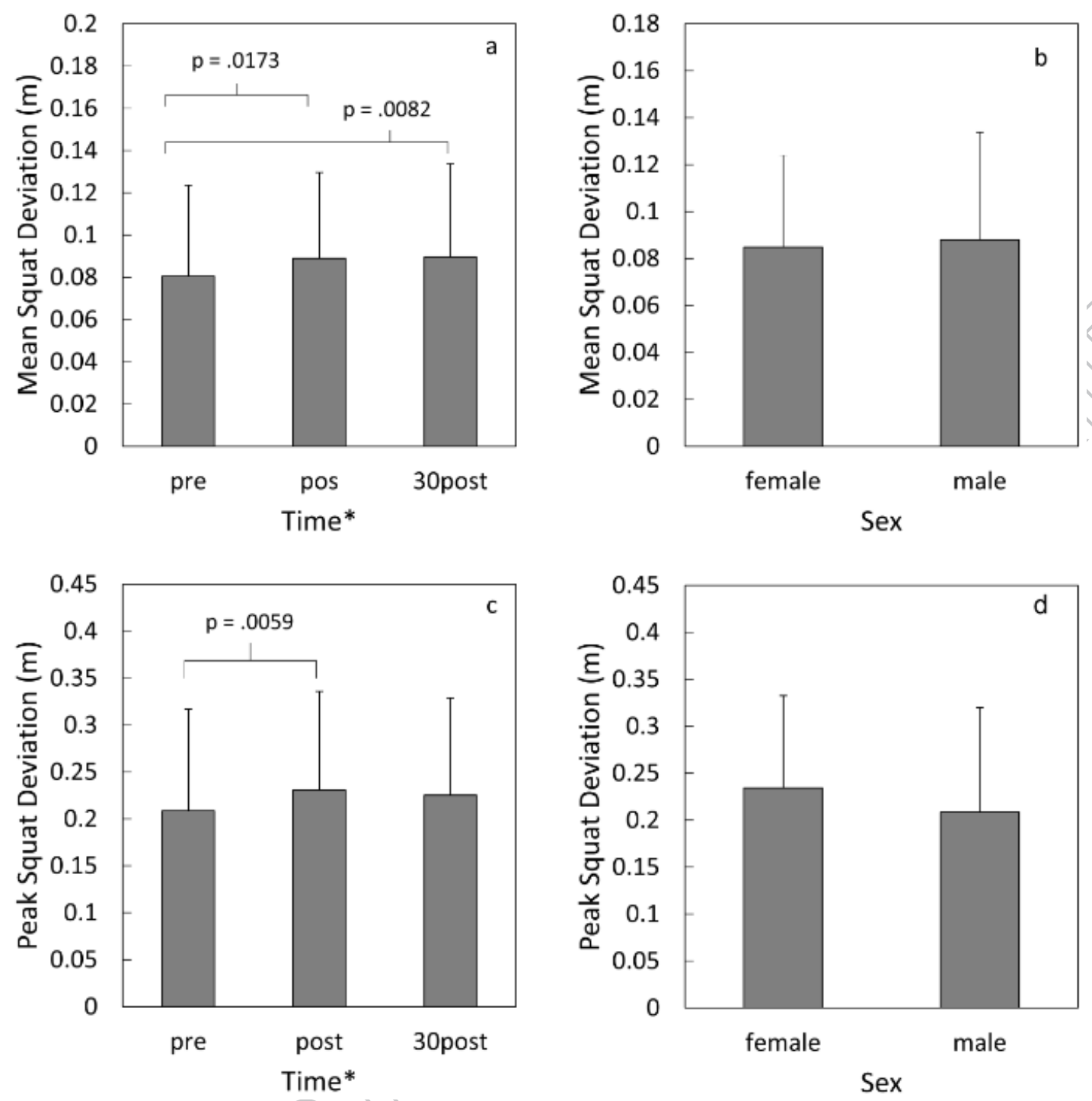
Supplement A. Body Segment Coordinate Systems for the Lower Limb

\begin{tabular}{|c|c|}
\hline Segment & Coordinate System Setup \\
\hline Coda Pelvis & $\begin{array}{l}\text { Origin: } \\
\text { The midpoint between ASIS markers. } \\
\text { XZ plane: } \\
\text { The plane defined by the left and right ASIS and PSIS markers. (A least-squares } \\
\text { plane is fit to the four targets). } \\
\text { X-axis: } \\
\text { The vector from the distal segment endpoint to the proximal segment endpoint } \\
\text { (midpoint of the PSIS markers to the midpoint of the ASIS markers), at the origin. } \\
\text { Y-axis: } \\
\text { The vector perpendicular to the XZ-plane, at the origin. } \\
\text { Z-axis: } \\
\text { The vector perpendicular to both the } Y \text {-axis and the X-axis, calculated as the cross- } \\
\text { product of X-by- } Y \text {, at the origin. }\end{array}$ \\
\hline Thigh & $\begin{array}{l}\text { Origin: } \\
\text { The hip joint center, as calculated using functional movement trials (Begon, } \\
\text { Monnet, \& Lacouture, 2007). } \\
\text { YZ plane: } \\
\text { The least-squares plane defined by the greater trochanter, the hip joint center, and } \\
\text { the lateral and medial knee makers The lateral and medial knee markers are } \\
\text { defined as the projections of the lateral and medial femoral condyle markers onto } \\
\text { the knee axis of rotation, as estimated from the functional knee joint trial } \\
\text { (Schwartz \& Rozumalski, 2005). } \\
\text { Y-axis: } \\
\text { The vector from the distal segment endpoint to the proximal segment endpoint } \\
\text { (midpoint of the knee markers to the functional hip joint center), at the origin. } \\
\text { X-axis: } \\
\text { The vector perpendicular to the YZ-plane, anteriorly. } \\
\text { Z-axis: } \\
\text { The vector perpendicular to both the Y-axis and the X-axis, calculated as the cross- } \\
\text { product of X-axis by the Y-axis from the hip joint center. }\end{array}$ \\
\hline Shank & $\begin{array}{l}\text { Origin: } \\
\text { The midpoint of the lateral and medial knee markers. } \\
\text { YZ-plane: }\end{array}$ \\
\hline
\end{tabular}




\begin{tabular}{|c|c|}
\hline & $\begin{array}{l}\text { The least-squares plane defined by the lateral and medial knee markers and the } \\
\text { lateral and medial malleoli. } \\
\text { Y-axis: } \\
\text { The vector from the distal segment endpoint to the proximal segment endpoint } \\
\text { (midpoint of the malleoli markers to the midpoint of the knee markers), at the } \\
\text { origin. } \\
\text { X-axis: } \\
\text { The X-axis is defined as the vector perpendicular to the YZ-plane, anteriorly. } \\
\text { Z-axis: } \\
\text { The Z-axis is defined as the vector perpendicular to both the Y-axis and the X-axis, } \\
\text { calculated as the cross-product of X-axis by the Y-axis, from the knee joint center. }\end{array}$ \\
\hline Foot & $\begin{array}{l}\text { By default, Visual 3D determines the frontal plane as the plane defined by the } \\
\text { segment endpoints. In the case of the virtual pelvis, femur, and tibia, this is } \\
\text { correct, and the frontal (YZ) plane is indeed defined by the markers. However, in } \\
\text { the foot, the plane defined by the markers is actually the transverse plane. } \\
\text { Therefore, the default coordinate system created by Visual 3D was rotated in the } \\
\text { software so that the transverse plane is the XZ-plane and the frontal plane is the } \\
\text { YZ-plane. } \\
\text { Origin: } \\
\text { The origin is defined as the midpoint between lateral and medial malleoli markers. } \\
\text { YZ-plane (original): } \\
\text { The least-squares plane defined by the lateral and medial malleoli and the } 1^{\text {st }} \text { and } \\
5^{\text {th }} \text { metatarsals. } \\
\text { Y-axis (original): } \\
\text { The vector from the midpoint of the } 1 \text { st and } 5^{\text {th }} \text { metatarsal markers and the } \\
\text { midpoint of the malleoli markers, at the origin. } \\
\text { X-axis (original): } \\
\text { The vector perpendicular to the YZ-plane, anteriorly. } \\
\text { Z-axis: } \\
\text { The vector perpendicular to both the Y-axis and the X-axis, calculated as the cross- } \\
\text { product of X-by-Y, from the origin. } \\
\text { The local coordinate system was then rotated in Visual } 3 D \text { such that the YZ-plane is } \\
\text { the frontal plane. }\end{array}$ \\
\hline
\end{tabular}

